\title{
Monetary Union, Real Exchange Rate, and Welfare
}

\author{
Hiroya Akiba \\ Waseda University
}

\begin{abstract}
This paper considers the effects of formation or new accession to a monetary union (MU) on itself ("ins") and the outsiders ("outs") as well. Since a MU inherently means a "large" entity, we construct a large country model to examine those effects in the context of economic growth. The closed-form solution of the terms of trade enables us to derive the plausible conclusions: (a) the terms of trade of the MU improves, (b) the real income of "outs" falls, implying a real transfer to the $M U$, and (c) the real exchange rate of the MU currency appreciates.
\end{abstract}

- JEL classification: F33, F36, F43

- Keywords: Exchange Rate, EU, Growth, Factor Accumulation

\section{Introduction}

The effects of monetary unions have attracted much attention both theoretically and empirically, partly because the euro has been successfully launched in 1999 for eleven of the fifteen EU countries, and partly because it was also adopted by Greece in 2002. The expansionary trend of the euro's adoption has been manifested by the recent participation in the ERM II by Estonia, Lithuania, and Slovenia in 2004, and Latvia, Cyprus and Malta in 2005. Furthermore, after the financial and currency crises witnessed in the last two decades, one of the central themes in international finance has been the choice of the appropriate international monetary system, in which a monetary union has been considered as one possible alternative belonging in the corner of the rigidly fixed exchange rate (hard peg) regimes.

\footnotetext{
*Corresponding address: School of Political Science \& Economics, Waseda University, 1-6-1 NishiWaseda, Shinjuku-ward, Tokyo 169-8050, Japan. E-mail: hiroyaakiba@ hotmail.com

@ $2007-C e n t e r$ for International Economics, Sejong Institution, All Rights Reserved.
} 
The costs and benefits of monetary unions and the related issues have mainly been studied within a framework of the Optimal Currency Area (OCA hereafter. Obstfeld and Rogoff, 1996, Chapter 9; Lafrance and St-Amant, 1999; McCallum, 2003; Frankel and Rose, 2002, among others). ${ }^{1}$ However, to the author's knowledge, the existing literature seems incomplete in the sense that it is devoid of important analysis in at least two respects. First of all, the main focal point of monetary unions has been their economic implications and consequences, and their effects on the member countries or regions only, and the possible beneficial or detrimental effects necessarily entailed by a monetary union on the outsiders (i.e., non-member countries) have been largely ignored. ${ }^{2}$ Secondly, since monetary unions necessarily mean that the monetary policy is conducted by a "large" country or economy, their effects on the outsiders will possibly be quite significant. It is not clear whether the large outsiders (e.g. the United States, or Japan) will gain or lose from the formation of, or an expansion of a currency union, and by what criteria the gains or losses should be evaluated. Thus, neglecting the examination of monetary and related consequences of market sizes for the outsiders seems to be partiality. ${ }^{3}$

With those two unsatisfactorily considered issues in mind, this paper considers a monetary union not only from its own, but also from the standpoint of the outsiders within a framework of two large countries. More specifically, we will examine the effects of monetary union (a large country) on the terms of trade, the national welfare level (approximated by the real income), and the real exchange rate of the other large countries (or economies) outside of the unions as well. It will become clear that the driving force of the latter two effects rests on the change in the terms of trade that will be affected by monetary unions, as emphasized by, e.g., Baldwin

${ }^{1}$ For example, based on the theory of the optimal currency area, Obstfeld and Rogoff (1996, chapter 9) identified that there are at least four benefits of a common currency system; reduced transaction costs, reduced accounting costs and greater predictability of relative prices, insulation from monetary disturbances and speculative bubbles, and less political pressure for trade protection. They also pointed out at least four costs; giving up independent monetary policy by each region, budgetary inflexibility of reducing real burden of public debt by inflation, political and strategic problems arising from distributing seigniorage revenues, and avoiding speculative attacks in the transition to a common currency.

${ }^{2}$ Carré and Collard (2003) and Dellas and Tavlas (2005) are notable exceptions. The former considers the sum of changes in welfare level and the latter examines the change in the real exchange of the global level.

\footnotetext{
${ }^{3} \mathrm{~A}$ large country model with particular emphasis on the Harrod-Balassa-Samuelson hypothesis has been considered in Asea and Mendoza (1994) and Balvers and Bergstrand (1997). Both of them explicitly incorporated the non-traded sector in their analyses, but the former was concerned with the Harrod neutral labor-augmented technological progress over time, and the latter assumed two different representative consumers with different preferences.
} 
and Wyplosz (2004, especially chapter 5). ${ }^{4}$ It will be shown that the changes in the terms of trade are in turn induced by changes in factor endowment and/or technological progress. ${ }^{5}$

The rest of the paper is organized as follows: In the next section II, a simple small country model is examined to show that both "ins" and "outs" of a monetary union are possibly affected as the real exchange rate moves to the opposite direction between before, and after the formation of, or new accession to, a monetary union. Section III presents our large country model. The model is a traditional Heckscher-Ohlin type of international trade that enables us to derive the closed-form solution of the terms of trade. The solution of the terms of trade is in effect the driving force to move the real income and the real exchange rate. Using the closed-form solutions, we examine the effects of economic growth, i.e. factor accumulation and technological progress, on the real income and the real exchange rate in section IV. Section V applies the results in the previous section to discuss the effects of the formation of or new accession to a monetary union. It will be shown that a monetary union causes a real transfer of income from "outs" to "ins", and has a possible detrimental effect on the welfare of the "outs". The real exchange rate is shown to move against the "outs" under our presumptions. Section VI concludes the paper.

\section{A Simple Small Country Model}

In order to help understand the model presented in the subsequent section III, a simple model in the monetary union literature is summarized in this section to consider the effects of the creation of or accession to a monetary union on a small outside country. Our focal point in this section rests on the change in the real exchange rate.

It is assumed that two goods are produced (and consumed) in a small country, one is the traded good and the other is the non-traded good, with two factors of production called labor $(L)$ and capital $(K)$, by the following production functions:

\footnotetext{
${ }^{4}$ The effects of changes in the terms of trade (and trade volumes) are also emphasized in the modern literature of a large country model of the Viner's type customs union. See, e.g. Kowalczyk (2000).

${ }^{5}$ Technological progress enhances total factor productivity, given the constant factor inputs. Thus, our analysis of changes in the real exchange rate (or the national welfare) driven by changes in the terms of trade through technological progress emphasizes the so-called Harrod-Balassa-Samuelson hypothesis (e.g., Obstfeld and Rogoff, 1996, chapter 4; Harrod, 1933; Balassa, 1964; Samuelson, 1964).
} 


$$
\begin{array}{ll}
Q^{T}=A^{T}\left(L^{T}\right)^{\theta_{T}}\left(K^{T}\right)^{1-\theta_{T}} & \left(0<\theta_{T}<1\right) \\
Q^{N}=A^{N}\left(L^{N}\right)^{\theta_{N}}\left(K^{N}\right)^{1-\theta_{N}} & \left(0<\theta_{N}<1\right)
\end{array}
$$

where $Q^{T}\left(Q^{N}\right)$ indicates domestic output of the traded (non-traded) good, and $A^{i}$ $(i=T, N)$ denotes (exogenously given) productivity in the $\mathrm{i}$-th sector. Both factors are assumed to be mobile across the two sectors, but only capital is mobile internationally. Assuming perfect competition in both sectors, profit maximization yields the standard FOCs that mean MPi $=$ RFRi relationships $(i=T, N)$, where MP and RFR stand for the marginal product and the real factor return, respectively. ${ }^{6}$ Differentiation of those FOCs yields the following system of equations:

$$
\left[\begin{array}{cccc}
\theta^{T} & 0 & 0 & 0 \\
0 & \theta^{N} & 0 & -1 \\
1-\theta^{T} & 0 & -1 & 0 \\
0 & 1-\theta^{N} & -1 & 1
\end{array}\right]\left[\begin{array}{c}
\hat{k}^{T} \\
\hat{k}^{N} \\
\hat{w} \\
\hat{p}
\end{array}\right]=\left[\begin{array}{c}
\hat{a}^{T} \\
\hat{a}^{N} \\
-\hat{a}^{T} \\
-\hat{a}^{N}
\end{array}\right]
$$

where the hat $\left(^{\wedge}\right)$ over variables means the rate of change, $\hat{k}^{i} \equiv d\left(K^{i} / L^{i}\right) /\left(K^{i} / L^{i}\right)$, $\hat{a}^{i} \equiv d A^{i} / A^{i}, \quad \hat{w} \equiv d W / W, \quad$ and $\hat{p} \equiv d P / P . W$ is the wage rate and $P$ is the relative price of non-traded good in terms of traded good, PN/PT. The system (3) consists of four equations with four endogenous variables, $\hat{k}^{T}, \hat{k}^{N}, \hat{w}$ and $\hat{p}$. It is a simple matter to confirm the solvability condition, but a quick glance at the system (3) shows that the system is block recursive, and thus easy to be solved. The rate of change in the relative price of a non-traded good is given by:

$$
\hat{p}\left(=\hat{p}^{N}-\hat{p}^{T}\right)=-\hat{a}^{N}+\left(\theta^{N} / \theta^{T}\right) \hat{a}^{T}
$$

Let us assume that equation (4) holds for any two small open economies, 1 and 2 , with the same capital intensity for the two goods ( $\mathrm{N}$ and T), i.e., $\theta^{T}$ and $\theta^{N}$ are the same for the two economies. It is further assumed that the purchasing power parity (PPP hereafter) holds for the traded good in the world market:

$$
P_{i}^{T}=S_{i} P_{0}^{T}
$$

where $P_{0}^{T}$ is the world price of the traded good which is given to the small economies, 1 and 2. $S_{i}(i=1,2)$ is the nominal (spot) exchange rate, expressed as

${ }^{6}$ See, e.g., Froot and Rogoff (1995, p.1674), Sarno and Taylor (2002), p.80, and Irandoust and Sj (2002), p.531, among others. 
units of currency I per unit of the international currency for international trade, say dollar. Equation (5) implies (through the so-called triangle arbitrage):

$$
P_{1}^{T} / P_{2}^{T}=S_{1} / S_{2} \equiv S
$$

and thus, the PPP also holds for a traded good between the two countries. Differentiation of (6) yields:

$$
\hat{p}_{1}^{T}=\hat{s}+p_{2}^{T}
$$

The consumers' price index (CPI, hereafter) for the two economies is assumed to be defined by:

$$
C P I_{j}=\left(P_{j}^{T}\right)^{\zeta}\left(P_{j}^{N}\right)^{1-\zeta} \quad(j=1,2 ; 0<\zeta<1)
$$

and its differential form is given by:

$$
c \hat{p} i=\zeta\left(\hat{p}_{j}^{T}\right)+(1-\zeta)\left(\hat{p}_{j}^{N}\right)
$$

The real exchange rate (RER) for country 1 is defined by CPI (Buiter and Grafe, 2002; Irandoust and Sjöö, 2002):

$$
R E R \equiv S\left(C P I_{2} / C P I_{1}\right)
$$

and differentiation yields:

$$
\hat{r e r}=\hat{s}+c \hat{p} i_{2}-c \hat{p} i_{1}
$$

Substituting (6'), (7') into (8') yields:

$$
\hat{r e r}=(1-\zeta)\left[\hat{s}-\left(\hat{a}_{2}^{N}-\hat{a}_{1}^{N}\right)+\left(\theta^{N} / \theta^{T}\right)\left(\hat{a}_{2}^{T}-\hat{a}_{1}^{T}\right)\right]
$$

To interpret equation (9), suppose the capital intensity is the same for both sectors, i.e., $\theta^{N}=\theta^{T}$ (Sarno and Taylor, 2000, p.80; Irandoust and $\mathrm{Sj}, 2002$, p. 531). Then, equation (9) reduces to:

$$
\hat{r e r}=(1-\zeta)\left[\hat{s}+\left(\hat{a}_{2}^{T}-\hat{a}_{2}^{N}\right)-\left(\hat{a}_{1}^{T}-\hat{a}_{1}^{N}\right)\right]
$$

From equation (9) and (9') the following Proposition 1 is straightforward:

Proposition 1 (Harrod-Balassa-Samuelson) ${ }^{7}$

(a) If $\hat{a}_{1}^{T}>\hat{a}_{2}^{T}$, then the real exchange rate of currency 1 appreciates, given $\hat{a}_{i}^{N}$. 
(b) If $\hat{a}_{1}^{N}>\hat{a}_{2}^{N}$, then the real exchange rate of currency 1 depreciates, given $\hat{a}_{i}^{T}$.

(c) For $\theta^{N}=\theta^{T}$, if $\hat{a}_{1}^{T}-\hat{a}_{1}^{N}>\hat{a}_{2}^{T}-\hat{a}_{2}^{N}$, then the real exchange rate of currency 1 appreciates, ceteris paribus.

This Proposition emphasizes that the changes in the real exchange rate is, in the long-run, dictated by the relative productivity differentials, as put forth by Harrod (1933), Balassa (1964), and Samuelson (1964). ${ }^{8}$

Having established Proposition 1, consider the effects of creating a monetary union of country 1 with a third small country (identified by suffix 0 ) on the outsider, i.e., country 2 . In order to simplify the analysis and emphasizes the significance of creating a monetary union for outsiders, we assume that, after the creation of a monetary union, country 0 uses country 1's currency. We also boldly assume that countries 1 and 0 have the same production functions for both $\mathrm{T}$ and $\mathrm{N}$, except productivity, $A^{T}$ and $A^{N}$. Let $\hat{a}_{M}^{T}$ and $\hat{a}_{M}^{N}$ be the growth rate of productivity in the monetary union. Then, the rate of change in the real exchange rate in equation (9) is replaced by:

$$
\hat{r e r}=(1-\zeta)\left[\hat{s}-\left(\hat{a}_{2}^{N}-\hat{a}_{M}^{N}\right)+\left(\theta^{N} / \theta^{T}\right)\left(\hat{a}_{2}^{T}-\hat{a}_{M}^{T}\right)\right]
$$

where suffix M signifies the monetary union constructed by countries 1 and 0 , and thus $\hat{a}_{M}^{i}(i=T, N)$ is defined by:

$$
\begin{array}{ll}
\hat{a}_{M}^{N} \equiv b \hat{a}_{1}^{N}+(1-b) \hat{a}_{0}^{N} & (0<b<1) \\
\hat{a}_{M}^{T} \equiv c \hat{a}_{1}^{T}+(1-c) \hat{a}_{0}^{T} & (0<c<1)
\end{array}
$$

where $b$ and $c$ are given constants, reflecting the relative quantity in the total production of $N$ and $T$ in the monetary union, respectively. Since $\hat{a}_{M}^{i}$ is a positive convex linear combination of $\hat{a}_{1}^{i}$ and $\hat{a}_{0}^{i}(\mathrm{i}=\mathrm{T}, \mathrm{N})$, it is clear that $\hat{a}_{M}^{i}>(<) \hat{a}_{1}^{i}$ according to whether $\hat{a}_{1}^{i}<(>) \hat{a}_{0}^{i}$. Thus, returning to Proposition 1, if (a) $\hat{a}_{M}^{T}<\hat{a}_{2}^{T}$, (b) $\hat{a}_{M}^{N}<\hat{a}_{2}^{N}$, and for $\theta^{N}=\theta^{T}$, if (c) $\hat{a}_{2}^{T}-\hat{a}_{2}^{N}>\hat{a}_{M}^{T}-\hat{a}_{M}^{N}$, ceteris paribus, then the real exchange rate of country 1 's currency moves to the opposite direction stated in Proposition 1. Since country 2 stays outside of the monetary union, the creation of a monetary union is shown to affect the small outsider significantly, in the sense

\footnotetext{
${ }^{7}$ See, e.g., Obstfeld and Rogoff (1996, p.210). See also Harrod (1933), Balassa (1964), Samuelson (1964), and Rogoff (1992). The Harrod-Balassa-Samuelson hypothesis is used to explore the long-run equilibrium real exchange rate by Mark and Choi (1997).

${ }^{8}$ Empirical validity of the Harrod-Balassa-Samuelson hypothesis to date has been weak. See, Asea and Mendoza (1994), Balvers and Bergstrand (1997), Irandoust and Sj (2002), Faria and Len-Ledesma (2003), among others.
} 
that the real exchange rate moves to the opposite direction predicted before the creation of the monetary union. ${ }^{9}$

\section{A Large Country Model}

Although the simple small country model for a monetary union presented and examined in the previous section explored rich economic implications dealing with the effects of creating a monetary union on the changes in the real exchange rate, their practical application is nonetheless limited, because monetary unions in the real world (e.g., the euro zone) are regarded as "large", in the sense that the countries in the zone can affect the terms of trade for outsiders (e.g., the United States which is also "large"). Thus, the analysis in a large country model is imperative to assess economic implications of creating monetary unions, and their effects through changes in the terms of trade on themselves as well as outsiders.

This section thus starts with construction of a model with two-country, twogood, and two factors of production that also emphasizes productivity; but we assume that both of the two sectors produce traded goods. The model to be presented below belongs to the traditional Neoclassical school, with perfect competition in the good and factor markets, full-employment of both factors, and well-behaved production functions. ${ }^{10}$ The model is thus more closely resembles the traditional Hechscher-Ohlin trade model, rather than the Harrod-BalassaSamuelson model that emphasizes the roll of non-traded goods whose relative price is affected by productivity.

The reasons for selecting a traditional model lie in the fact that, first of all, in the existing monetary union (or economic integration in general) changes in the terms of trade have been one of the central issues to be examined (e.g., Baldwin and

\footnotetext{
${ }^{9}$ Implications for a small country to participate in an existing monetary union are examined by Alesina and Barro (2002). They discussed the trade-offs between the benefits and costs of adopting another country's currency. Kowalczyk (2000) also examined a small country case and concluded that the country gains, under certain conditions, from mutual equi-proportionate tariff rate reductions. von Furstenberg and Teolis (2002) construct both a large country and a small country models that minimize the social loss functions consisting of inflation and supply shocks. They found that a small country may gain under certain conditions from accession to a monetary union.

${ }^{10}$ For the analytical framework, see, e.g., Gandolfo (1994, chapter 6), Jensen and Wang (1997), Takayama (1972), Alesina and Barro (2002), among others. Asea and Mendoza (1994) and Balvers and Bergstrand (1997) considered a large country model with special emphasis on the Harrod-Balassa-Samuelson hypothesis. Instead of considering the effects of productivity differentials on the relative price of nontraded good, we are interested in the effects on the terms of trade, as will be clear in what follows.
} 
Wyplosz, 2004), and they are better analyzed within a traditional Heckscher-Ohlin trade model. Then, it may not be necessary to assume the existence of non-traded good, as the terms of trade refer to the ratio of traded good prices.

Secondly, since our main focal point rests on the effects of creation of, or accession to, a monetary union, and since those effects are closely related to, and reflected in, changes in the terms of trade as will be explored later, a traditional model is a better choice. The reason for it rests on a simple fact that it enables us to derive the closed-form solutions for the endogenous variables, e.g. the terms of trade, and those solutions make our inferences and conclusions easier and clearer than ad hoc calibration required for those derived from unnecessarily complex models.

Thirdly, from a practical point of view, the creation of or accession to a monetary union can be identified as economic growth from the standpoint of the member countries. Then, since the effects of economic growth have been examined in the traditional Heckscher-Ohlin model, it may not be necessary to assume the existence of non-traded goods.

Fourthly, if the purpose of constructing the Harrod-Balassa-Samuelson model is to examine the effects of productivity differentials, it is not necessarily the only model. Those effects will also be analyzed within a framework of the traditional Heckscher-Ohlin model with appropriately specified production functions.

Moreover, fifthly, a large country model incorporating the Harrod-BalassaSamuelson hypothesis was considered in a stochastic dynamic two-sector general equilibrium model by Asea and Mendoza (1994), and in a long-run general equilibrium open-economy macroeconomic model by Balvers and Bergstrand (1997). Both of them imposed specific assumptions to derive the closed-form solutions: The former assumed the Harrod-neutral labor-augmented technological progress, and the instantaneous felicity function having a constant elasticity of substitution. The latter assumed that there are two different types of representative consumers, one with a utility function with isoelasticity, and the other with the Cobb-Douglas form. Those specific assumptions were imposed as a necessary eclectic compromise to cope with a trade-off between losses of generality and gains from closed-form solutions.

Finally, to the author's knowledge, empirical validity of the Harrod- BalassaSamuelson hypothesis on the real exchange rate to date has been rather unfavorable, although, as is usually the case for empirical studies, the results have been mixed and conflicting. ${ }^{11,12}$ 
Let us start with the supply side. To facilitate comparison with the model in the last section, the production functions of the two traded goods $(X$ and $Y)$ are specified by: ${ }^{13}$

$$
\begin{array}{cc}
X=A_{X}\left(L_{X}\right)^{\theta_{L X}}\left(K_{X}\right)^{\theta_{K X}} & \theta_{L X}+\theta_{K X}=1, \theta_{i X}>0 \\
Y=A_{Y}\left(L_{Y}\right)^{\theta_{L Y}}\left(K_{Y}\right)^{\theta_{K Y}} & \theta_{L Y}+\theta_{K Y}=1, \theta_{i Y}>0
\end{array}
$$

where $L_{i}$ and $K_{i}$ stand for labor and capital inputs to the $\mathrm{i}$-th sector $(i=\mathrm{X}, \mathrm{Y}) . A_{i}$ denotes, as before, productivity in the i-th sector, which is assumed exogenous. Assuming factor mobility of $K$ and $L$ across sectors, perfect competition yields:

$$
\begin{gathered}
W=P \mu_{X}=Q \mu_{Y} \\
R=P v_{X}=Q v_{Y}
\end{gathered}
$$

where $W$ and $R$ are the wage rate and the rental rate, $\mu_{i}$ and $v_{i}(i=X, Y)$ are the marginal product of labor and capital in the i-th sector, and $P$ and $Q$ are the price of good $X$ and $Y$, respectively. It is assumed that $P=Q=1$, initially. Thus, it is straightforward to obtain $k_{i} \equiv K_{i} / L_{i}=\left[\left(1-\theta_{L i}\right) / \theta_{L i}\right](W / R), \quad(i=X, Y)$, which yields:

\footnotetext{
${ }^{11}$ Asea and Mendoza (1994) found that, using annual data of 1970-1985 for 14 OECD countries with 20 sectors, and applying the Hodorick-Prescott filter for a linear trend, the long-run relative prices are of little help in explaining long-run, cross-country differences in the level of the real exchange rate. Balvers and Bergstrand (1997) obtained, using the OECD panel data from 1973 to mid-1980s and the 2SLS method to deal with the simultaneous equation bias with relative production and consumption, the estimates largely consistent with the prediction by the Harrod-Balassa-Samuelson hypothesis. Irandoust and $\mathrm{Sj}$ (2002) also investigated the empirical relevance of the Harrod- Balassa-Samuelson hypothesis using the six OECD counties data, and found little support for the productivity bias hypothesis. In a recent paper by Faria and Leon-Ledesma (2003) using the co-integration technique with the bounds testing approach for the quarterly data of Germany, Japan, United Kingdom, and the United States from 1960:1 to 1996:4, their empirical results do not show supportive evidence for the Harrod- Balassa-Samuelson effect in the long-run.

${ }^{12}$ There are several articles within a framework of the so-called New Open Economy Macroeconomics for monetary integration with 2 (or 3 ) large countries. Assuming intertemporal maximization, they examine the effects of asymmetric shocks on exchange rate volatility or welfare levels with assumptions of nominal rigidity. However, since the solutions are inevitably highly non-linear, their conclusions are necessarily ambiguous, except those derived from calibration with ad hoc assumptions on underlying parameters. See, for examples, Carré and Collard (2003), Ching and Devereux (2003), Kollmann (2004), Dellas and Tavlas (2005).

${ }^{13}$ For simplicity's sake, the country is not designated at this stage. The production functions and the subsequent analysis are applicable for both countries, unless otherwise mentioned.
} 


$$
\begin{aligned}
& \hat{K}_{X}-\hat{L}_{X}=\left(L_{X} / K_{X}\right)\left[\left(1-\theta_{L X}\right) / \theta_{L X}\right](\hat{W}-\hat{R}) \\
& \hat{K}_{X}-\hat{L}_{X}=\left(L_{X} / K_{X}\right)\left[\left(1-\theta_{L X}\right) / \theta_{L X}\right](\hat{W}-\hat{R})
\end{aligned}
$$

and the assumption of full employment of labor and capital yields:

$$
\begin{gathered}
\left(L_{X} / L\right) \hat{L}_{X}+\left(L_{Y} / L\right) \hat{L}_{Y}=\hat{L} \\
\left(K_{X} / K\right) \hat{K}_{X}+\left(K_{Y} / K\right) \hat{K}_{Y}=\hat{K}
\end{gathered}
$$

The system of equation (14-1)-(14-4) is summarized as:

$$
\left[\begin{array}{cccc}
1 & -1 & 0 & 0 \\
0 & 0 & 1 & -1 \\
0 & L_{X} / L & 0 & L_{Y} / L \\
K_{X} / K & 0 & K_{Y} / K & 0
\end{array}\right]\left[\begin{array}{c}
\hat{K}_{X} \\
\hat{L}_{X} \\
\hat{K}_{Y} \\
\hat{L}_{Y}
\end{array}\right]=\left[\begin{array}{c}
D_{X}(\hat{W}-\hat{R}) \\
D_{Y}(\hat{W}-\hat{R}) \\
\hat{L} \\
\hat{K}
\end{array}\right]
$$

where $D_{i} \equiv\left[\left(1-\theta_{L i}\right) / \theta_{L i}\right] / k_{i}$ and $k_{i}$ in this section is defined by $k_{i} \equiv K_{i} / L_{i}$, ( $i=X, Y$ ) The system of equation (14-5) is not block recursive any more, but solved for $\hat{K}_{X}, \hat{L}_{X}, \hat{K}_{Y}$, and $\hat{L}_{Y}$. Using those solutions with production functions, the rate of change in production is expressed as: ${ }^{14}$

$$
\begin{aligned}
\hat{X}= & \frac{1}{k_{X}-k_{Y}}\left[\frac{K}{L_{X}}\left(\hat{K}-k_{Y} \frac{L}{K} \hat{L}\right)\right]-\frac{(\hat{W}-\hat{R})}{L_{X}\left(k_{X}-k_{Y}\right)} \\
& \left\{\frac{1-\theta_{L X}}{k_{X} \theta_{L X}} L_{X}\left[\theta_{L X} k_{X}+\left(1-\theta_{L X}\right) k_{Y}\right]+\left(\frac{1-\theta_{L Y}}{\theta_{L Y}}\right) L_{Y}\right\}+\hat{a}_{X} \\
\hat{Y}= & \frac{1}{k_{X}-k_{Y}}\left[\frac{-K}{L_{X}}\left(\hat{K}-k_{X} \frac{L}{K} \hat{L}\right)\right]+\frac{(\hat{W}-\hat{R})}{L_{Y}\left(k_{X}-k_{Y}\right)} \\
& \left\{L_{X} \frac{1-\theta_{L X}}{\theta_{L X}}+\frac{1-\theta_{L Y}}{k_{Y} \theta_{L Y}} L_{Y}\left[\theta_{L Y} k_{Y}+\left(1-\theta_{L Y}\right) k_{X}\right]\right\}+\hat{a}_{Y}
\end{aligned}
$$

Using the Euler equations for homogeneous property, and definitions of elasticities of production $\left(\varepsilon_{\mathrm{X}}\right.$ and $\left.\varepsilon_{\mathrm{Y}}\right)$ evaluated at the initial equilibrium point, equation (15) is simplified as:

\footnotetext{
${ }^{14}$ For derivation of the following equations, inequalities, and definitions, see the Appendix section.
} 


$$
\begin{gathered}
\hat{X}=\frac{\lambda_{X}}{k_{X}-k_{Y}}+\varepsilon_{X}(p-q)+\varepsilon_{X}\left(\hat{a}_{X}-\hat{a}_{Y}\right)+\hat{a}_{X} \\
\hat{Y}=\frac{-\lambda_{Y}}{k_{X}-k_{Y}}-\varepsilon_{Y}(p-q)+\varepsilon_{Y}\left(\hat{a}_{Y}-\hat{a}_{X}\right)+\hat{a}_{Y}
\end{gathered}
$$

where:

$$
\lambda_{X} \equiv\left(K / L_{X}\right)\left(\hat{K}-k_{Y} L \hat{L} / K\right) \text { and } \lambda_{Y} \equiv\left(K / L_{Y}\right)\left(\hat{K}-k_{X} L \hat{L} / K\right)
$$

This completes the description of the supply side.

We now move on the description of the demand side of the economy. It is assumed that good $X$ is exported from country 1 (denoted by $X_{12}$ ), and good $Y$ is exported from country 2 (denoted by $Y_{21}$ ). Thus, the consumers' demand function for the imported good for each country is assumed as:

$$
\begin{aligned}
& Y_{1}+Y_{21}=f_{1}\left(Q / P, Z_{1}\right) \\
& X_{2}+X_{12}=f_{2}\left(P / Q, Z_{2}\right)
\end{aligned}
$$

where $Z_{i}$ is the real income of the i-th country. Differentiation of (17) and an assumption of the initial equilibrium of the balance of payments yields: ${ }^{15}$

$$
m_{1} x_{1}-\left(1-m_{1}\right) y_{1}+\left(1-m_{2}\right)-m_{2}=-(p-q) Y_{21}\left[\eta_{1}^{\prime}+\eta_{2}^{\prime}+m_{1}+m_{2}-1\right]
$$

The coefficient of the right-hand side of equation (18) is defined as:

$$
\Delta \equiv \eta_{1}^{\prime}+\eta_{2}^{\prime}+m_{1}+m_{2}-1
$$

which has been known as the Marshall-Lerner condition in trade literature. If we implicitly assume that the original equilibrium point for the commodity markets is (locally) stable, it means that $\Delta$ is positive (i.e., $\Delta>0$ ).

This completes the description of our model of two large countries. In the next section, we will examine the effects of economic growth (i.e., increases in factor supply and technological progress) on the terms of trade, the welfare level (approximated by the real income), and the real exchange rate.

\section{Effects of Economic Growth}

This section utilizes the framework laid in the last section for the two large countries to examine the effects of economic growth on the terms of trade, national welfare (approximated by the real income), and the real exchange rate.

${ }^{15}$ For the definitions of $\eta_{i}(i=1,2)$, see equation (A13) in Appendix. 
Since commodity $X$ is assumed to be exported from country 1 to 2, the assumption of free trade ensures the law of one price $P_{1}=S P_{2}$ and $Q_{1}=S Q_{2} \cdot{ }^{16}$ This implies $P_{1} / Q_{1}=P_{2} / Q_{2}=P / Q$. Thus, the change in the terms of trade is expressed by $p-q$ for country 1 .

National welfare is assumed to be represented by the real income. Since the change in the real income is derived from two sources, one being the changes in the prices of the traded goods and the other being the changes in output, it is expressed as:

$$
\begin{aligned}
& z_{1}=(p-q) Y_{21}+x_{1}+y_{1} \\
& z_{2}=(q-p) Y_{21}+x_{2}+y_{2}
\end{aligned}
$$

where we make use of the fact that $Y_{21}=X_{12}$ at the initial equilibrium point of the balance of payments, $B_{1}=P_{1} X_{12}-Q_{2} Y_{21}=0$.

The real exchange rate between the two large countries is similar to the one discussed in section II, $R E R \equiv S\left(C P I_{2} / C P I_{1}\right)$, where $S$ is, as before, the nominal (spot) exchange rate, expressed as units of currency 1 per unit of currency 2 . We assume, similar to the one defined in section II, that $C P I_{1} \equiv P^{\zeta} Q^{1-\zeta}$ while $C P I_{2} \equiv Q^{\zeta} P^{1-\zeta}$, where $\zeta(0<\zeta<1)$ is the weight attached to the export good for both countries. Thus, the rate of change in the real exchange rate is expressed as:

$$
\hat{r e r}=\hat{s}+\tau(\hat{p}-\hat{q}) \quad \tau \equiv 2 \zeta-1
$$

Since $1>\zeta>0$, the coefficient $\tau$ must be $\tau \in(-1,1)$.

Since the word "growth" means either an increase in factor supplies or technological progress (or both), we start the analysis in this section with the former, i.e. an increase in factor supplies, followed by the latter, i.e. technological progress.

\section{IV-1. Factor Accumulation}

Let us assume that only one of the countries, say country 1 , is subject to the growth in factor supplies, given technological progress. Thus, this section assumes, in terms of our notation, $\hat{a}_{i j}=0(i=X, Y ; j, 1,2), \hat{K}_{2}=\hat{L}_{2}=0$, but $\hat{K}_{1} \geq 0$ and $\hat{L}_{1} \geq 0$. Recalling our definitions, $x_{i}=d X_{i}, y_{i}=d Y_{i}, \hat{X}_{i}=d X_{i} / X_{i}$, and $\hat{Y}_{i}=d Y_{i} / Y_{i}$, it can be shown that:

\footnotetext{
${ }^{16}$ Needless to say, we abstract from any trade frictions such as transport costs or more generally transaction costs.
} 


$$
p-q=\frac{-1}{\Delta Y_{21}\left(k_{X 1}-k_{Y 1}\right)}\left[m_{1} \lambda_{X 1} X_{1}+\left(1-m_{1}\right) \lambda_{Y 1} Y_{1}\right]
$$

Thus, if we assume that the exported good of country 1 is more capital intensive than the imported good $\left(k_{X 1}-k_{Y 1}>0\right)$, then the necessary and sufficient condition for the terms of trade for country 1 being improved is:

$$
m_{1} \lambda_{X 1} X_{1}+\left(1-m_{1}\right) \lambda_{Y 1} Y_{1}<0
$$

or, using the definitions of $\lambda_{X 1}$ and $\lambda_{Y 1}$ (23) can be rewritten as:

$$
m_{1} X_{1}\left(\frac{K_{1}}{L_{X 1}}\right)\left[\hat{K}_{1}-k_{Y 1}\left(\frac{L_{1}}{K_{1}}\right) \hat{L}_{1}\right]+\left(1-m_{1}\right) Y_{1}\left(\frac{K_{1}}{L_{Y 1}}\right)\left[\hat{K}_{1}-k_{X 1}\left(\frac{L_{1}}{K_{1}}\right) \hat{L}_{1}\right]<0
$$

This condition is simplified under the initial conditions $\mu_{X}=v_{X}=1$ :

$$
d K_{1}<\kappa d L_{1}
$$

where:

$$
\kappa \equiv\left[\left(1-\theta_{L X 1}\right)+m_{1}\left(\theta_{L X 1}-\theta_{L Y 1}\right)\right] /\left[\theta_{L X 1}+m_{1}\left(\theta_{L Y 1}-\theta_{L X 1}\right)\right]
$$

It is clear that $\kappa \geq 0$, because of our assumption $1>\theta_{L Y 1} \geq \theta_{L X 1}>0$ and $1>m_{1}>0$. Thus, our finding up to here for the effects of factor accumulation is summarized in the following Proposition $2::^{17,18}$

Proposition 2 The change in the terms of trade for country 1

Assume $\hat{a}_{i j}=0(i=X, Y ; j, 1,2), \hat{K}_{2}=\hat{L}_{2}=0, \hat{K}_{1} \geq 0, \hat{L}_{1} \geq 0, k_{X 1}>k_{Y 1}$ and $X_{1}$ is exported from country 1 to 2 . Then,

$p-q\left\{\begin{array}{l}> \\ = \\ <\end{array}\right\} 0$ according to whether $d K_{1}\left\{\begin{array}{l}< \\ = \\ >\end{array}\right\} \kappa d L_{1}$, where $\kappa$ is defined in (24-3).

We now turn to examine the change in real income by factor accumulation. Let us continue to assume that factor accumulation is observed only in country $1 ; \hat{K}_{1} \geq 0$ and $\hat{L}_{1} \geq 0$, but $\hat{K}_{2}=\hat{L}_{2}=0$. This implies that $x_{2}\left(\equiv d X_{2}\right)=y_{2}\left(\equiv d Y_{2}\right)=0$

\footnotetext{
${ }^{17}$ When, in general, growth in factor supplies occurs in both countries, the terms of trade for country 1 is expressed as: $p-q=\frac{-1}{\Delta Y_{21}}\left\{\frac{m_{1} \lambda_{X 1} X_{1}+\left(1-m_{1}\right) \lambda_{Y 1} Y_{1}}{k_{X 1}-k_{Y 1}}+\frac{\left(1-m_{2}\right) \lambda_{X 2} X_{2}+m_{2} \lambda_{Y 2} Y_{2}}{k_{X 2}-k_{Y 2}}\right\}$

${ }^{18}$ In the rest of this paper, the Marshall-Lerner condition for stability of the equilibrium point of the commodity markets is assumed to be always satisfied, i.e., $\Delta>0$,
} 
The change in the real income for country 2 under these circumstances is, from equation (20-2), measured by $z_{2}=(q-p) Y_{21}$, which is, upon substitution of (22):

$$
z_{2}=\frac{1}{\Delta\left(k_{X 1}-k_{Y 1}\right)}\left[m_{1} \lambda_{X 1} X_{1}+\left(1-m_{1}\right) \lambda_{Y 1} Y_{1}\right]
$$

On the other hand, however, the change in the real income for country 1 is slightly more involved, as it is measured by (20-1), $z_{1}=(p-q) Y_{21}+x_{1}+y_{1}$ which is equivalently expressed, upon substitution of $\lambda_{X}$ and $\lambda_{Y}$ :

$$
z_{1}=\frac{1}{\Delta\left(k_{X 1}-k_{Y 1}\right)}\left[\left(\Delta-m_{1}\right)\left(\lambda_{X 1} X_{1}-\lambda_{Y 1} Y_{1}\right)-\lambda_{Y 1} Y_{1}\right]
$$

Thus, the following Proposition 3 is immediate:

Proposition 3 The Change in the Real Income

Retaining the assumptions put forth in the previous Propositions, the change in the real income of the i-th country $\left(z_{i}\right)$ is:

$$
\begin{gathered}
z_{1}=\frac{1}{\Delta\left(k_{X 1}-k_{Y 1}\right)}\left[\left(\Delta-m_{1}\right)\left(\lambda_{X 1} X_{1}-\lambda_{Y 1} Y_{1}\right)-\lambda_{Y 1} Y_{1}\right] \\
z_{2}=\frac{1}{\Delta\left(k_{X 1}-k_{Y 1}\right)}\left[m_{1} \lambda_{X 1} X_{1}+\left(1-m_{1}\right) \lambda_{Y 1} Y_{1}\right]
\end{gathered}
$$

Remarks: Using the definition (24-3) the following is apparent:

$$
z_{2}\left\{\begin{array}{l}
> \\
= \\
<
\end{array}\right\} 0 \text { according to whether } d K_{1}\left\{\begin{array}{l}
< \\
= \\
>
\end{array}\right\} \kappa d L_{1}
$$

\section{Corollary}

Factor accumulation in country 1 enhances the world real income (defined by the sum of two countries' real incomes):

$$
z_{1}+z_{2}=\frac{\lambda_{X 1} X_{1}-\lambda_{Y 1} Y_{1}}{k_{X 1}-k_{Y 1}}>0
$$

The proof follows immediately from equation (A22) in the Appendix which implies that, $k_{X 1}-k_{Y 1}$ and $\lambda_{X 1} X_{1}-\lambda_{Y 1} Y_{1}$ have the same sign, since the both marginal products are assumed positive with $k_{1}>0$ and $l_{1}>0$. Thus, the Corollary clearly means that factor accumulation is a positive-sum game. 
Next the change in the real exchange rate between the two countries is examined by substituting (22) into (21). Assuming that the nominal exchange rate is either closely approximated by a random walk process, stable over time, or rigidly fixed, then we can regard $\hat{s}=0$. Thus, using (21), the change in the real exchange rate, rêr, is:

$$
\begin{array}{r}
r \hat{e} r\left\{\begin{array}{l}
> \\
<
\end{array}\right\} 0 \text { according to whether } p-q\left\{\begin{array}{l}
> \\
<
\end{array}\right] 0 \text { for } 1>\zeta>1 / 2 \\
\text { but } p-q\left\{\begin{array}{l}
< \\
= \\
>
\end{array}\right\} 0 \text { for } 1 / 2>\zeta>-1
\end{array}
$$

In other words, the weight attached to the price level of their own export commodity in their CPI comes into the process of determining the sign in (27) as another complicating element. As well-documented, however, for large countries the trade sector has been relatively "small" compared to small open countries. For example, the openness index for the United Sates and Japan in 2003 is $26 \%$ and $27 \%$, respectively. ${ }^{19}$ Thus, we could safely assume that $1 / 2>\zeta(>0)$, which means $2 \zeta-1<0$, and this in turn implies that (27) is modified to:

$$
\operatorname{rer}\left\{\begin{array}{l}
> \\
<
\end{array}\right\} 0 \text { according to whether } p-q\left\{\begin{array}{l}
< \\
= \\
>
\end{array}\right\} 0
$$

We can summarize our discussion on the change in the real exchange rate in the following Proposition 4:

Proposition 4 The Change in the Real Exchange Rate

Retaining the assumptions put forth in the previous Propositions, the change in the real exchange rate of country 1 is:

\footnotetext{
${ }^{19}$ The openness index calculated by the author is exports plus imports (of goods, service, and income) divided by GNP (all measured by the current US dollar). The source is the World Development Indicator on-line.
} 


$$
\hat{\operatorname{er}}\left\{\begin{array}{l}
> \\
<
\end{array}\right\} 0 \text { according to whether } p-q\left\{\begin{array}{l}
< \\
= \\
>
\end{array}\right\}
$$

where it is assumed that $1 / 2>\zeta(>0)$.

\section{Technological Progress}

This subsection examines the effects of the second meaning of "economic growth", i.e., technological progress, given the factor endowment for two large countries $\left(\hat{K}_{i}=\hat{L}_{i}=0 ; i=1,2\right)$. Parallel to the analyses in the previous subsection, and to make our argument tractable, let us further assume that only country 1 experiences technological progress, i.e., $\hat{a}_{j 1} \geq 0$ but $\hat{a}_{j 2} \geq 0$ for $j=X$ and $Y$.

Evaluating equations (16-1) and (16-2) at the initial equilibrium point, it can be shown that $\hat{X}_{1}=\varepsilon_{X 1}\left(\hat{a}_{X 1}-\hat{a}_{Y 1}\right)+\hat{a}_{X 1}, \hat{X}_{2}=0, \hat{Y}_{1}=\varepsilon_{Y 1}\left(\hat{a}_{Y 1}-\hat{a}_{X 1}\right)+\hat{a}_{Y 1}$ and $\hat{Y}_{2}=0$. Substituting those relationships into equation (18) yields:

$$
p-q=\frac{-1}{\Delta Y_{21}}\left[m_{1} X_{1} \hat{a}_{X 1}-\left(1-m_{1}\right) Y_{1} \hat{a}_{Y 1}+\left(\hat{a}_{X 1}-\hat{a}_{Y 1}\right) X_{1} \varepsilon_{X 1}\right]
$$

Thus, the change in the terms of trade for country 1 is:

$$
p-q\left\{\begin{array}{l}
< \\
>>
\end{array}\right\} 0 \text { according to whether }\left[m_{1} X_{1} \hat{a}_{X 1}-\left(1-m_{1}\right) Y_{1} \hat{a}_{Y 1}+\left(\hat{a}_{X 1}-\hat{a}_{Y 1}\right) X_{1} \varepsilon_{X 1}\right]\left\{\begin{array}{l}
< \\
= \\
>
\end{array}\right\} 0
$$

It should be noted that the condition noted in (28') for the sign of $p-q$ is both necessary and sufficient. Let us consider special cases of (28). First, assume that only the import competing industry of country 1 (i.e., $Y_{1}$ ) undergoes technological progress, meaning that $\hat{a}_{Y 1}>0$ while $\hat{a}_{X 1}=0$. Then, $p$ - $q$, the terms of trade move in favor of country $1(p-q>0)$, since from (28):

$$
p-q=\frac{-1}{\Delta Y_{21}}\left[-\left(1-m_{1}\right) Y_{1} \hat{a}_{Y 1}-\hat{a}_{X 1} X_{1} \varepsilon_{X 1}\right]>0
$$

On the other hand, however, it is apparent that the terms of trade move against country $1(p-q<0)$, if only the export industry undergoes technological progress, i.e., $\hat{a}_{X 1}>0$ while $\hat{a}_{Y 1}=0$ : 


$$
p-q=\frac{-1}{\Delta Y_{21}}\left[m_{1} X_{1} \hat{a}_{X 1}+\hat{a}_{X 1} X_{1} \varepsilon_{X 1}\right]<0
$$

Our finding up to here is summarized as Proposition 5 below:

Proposition 5 The Changes in the Terms of Trade

Assume that only country 1 experiences technological progress under the given factor endowment. The terms of trade for country 1 moves:

(a) in favor of country 1 if only the import-competing sector experiences technological progress, but

(b) against country 1 if only the export sector experiences technological progress. However, in general,

(c) to either direction, if both sectors undergo technological progress, depending on the (necessary and sufficient) condition mentioned in (28').

Once the change in the terms of trade is determined as in Proposition 5, the change in the real income is similarly examined. From (20-1) and (20-2), with our assumptions of $K_{i}=L_{i}=0$, they are: $z_{1}=(p-q) Y_{21}+x_{1}+y_{1}$ and $z_{2}=(p-q)$ $Y_{21}+x_{2}+y_{2}$. Also from (16-1) and (16-2) we have $x_{1}=\left[\varepsilon_{X 1}\left(\hat{a}_{X 1}-\hat{a}_{Y 1}\right)+\hat{a}_{X 1}\right]$ $X_{1}, y_{1}=\left[\varepsilon_{Y 1}\left(\hat{a}_{Y 1}-\hat{a}_{X 1}\right)+\hat{a}_{Y 1}\right] Y_{1}$, but $x_{2}=y_{2}=0$ because of our assumption of $\hat{a}_{X 2}=\hat{a}_{Y 2}=0$. Thus, $z_{2}$ reduces to $(q-p) Y_{21}\left[=-(p-q) Y_{21}\right]$, or from (28):

$$
z_{2}=\frac{1}{\Delta}\left[m_{i} X_{1} \hat{a}_{X 1}-\left(1-m_{1}\right) Y_{1} \hat{a}_{Y 1}+\left(\hat{a}_{X 1}-\hat{a}_{Y 1}\right) X_{1} \varepsilon_{X 1}\right]
$$

Thus, the change in the real income of country 2 is:

$$
z_{0}\left\{\begin{array}{l}
> \\
= \\
<
\end{array}\right\} 0 \text { according to whether }\left[m_{1} X_{1} \hat{a}_{X 1}-\left(1-m_{1}\right) Y_{1} \hat{a}_{Y 1}+\left(\hat{a}_{X 1}-\hat{a}_{Y 1}\right) X_{1} \varepsilon_{X 1}\right]\left\{\begin{array}{l}
> \\
= \\
<
\end{array}\right\} 0
$$

If only the import-competing sector experiences technological progress $\left(\hat{a}_{Y 1}>0\right.$ but $\left.\hat{a}_{X 1}=0\right)$, then $z_{2}=(1 / \Delta)\left[-\left(1-m_{1}\right) Y_{1}-X_{1} \varepsilon_{X 1}\right] \hat{a}_{Y 1}<0$, meaning that the real income of country 2 declines as a result of technological progress in country 1 . However, in the opposite case, where only the export sector experiences technological progress $\left(\hat{a}_{X 1}>0\right.$ but $\left.\hat{a}_{Y 1}=0\right)$, then $z_{2}=(1 / \Delta)\left[m_{1} X_{1}-X_{1} \varepsilon_{X 1}\right]$ $\hat{a}_{X 1}>0$, the real income of country 2 increases. 
The change in the real income of country 1 is, as before, slightly more complicated, but it can be shown that:

$$
z_{1}=\frac{1}{\Delta}\left[\left(\Delta-m_{1}+1\right) Y_{1} \hat{a}_{Y 1}+\left(\Delta-m_{1}\right) X_{1} \hat{a}_{X 1}-\left(\hat{a}_{X 1}-\hat{a}_{Y 1}\right) \mathcal{E}_{X 1} X_{1}\right]
$$

which has an ambiguous sign. However, the sign is determined when only the import sector of country 1 experiences technological progress, in which case $z_{1}$ reduces to:

$$
z_{1}=\frac{1}{\Delta}\left[\left(\Delta-m_{1}+1\right) Y_{1}+\varepsilon_{X 1} X_{1}\right] \hat{a}_{Y 1}>0
$$

Our finding up to here is summarized as Proposition 6 below:

Proposition 6 The Changes in the Real Income

Retaining the assumptions in the last Proposition, technological progress in country 1 moves the real incomes of country 1 and 2 to:

$$
\begin{gathered}
z_{1}=\frac{1}{\Delta}\left[\left(\Delta-m_{1}+1\right) Y_{1} \hat{a}_{Y 1}+\left(\Delta-m_{1}\right) X_{1} \hat{a}_{X 1}-\left(\hat{a}_{X 1}-\hat{a}_{Y 1}\right) \varepsilon_{X 1} X_{1}\right] \\
z_{1}=\frac{1}{\Delta}\left[m_{1} X_{1} \hat{a}_{X 1}-\left(1-m_{1}\right) Y_{1} \hat{a}_{Y 1}+\left(\hat{a}_{X 1}-\hat{a}_{Y 1}\right) X_{1} \varepsilon_{X 1}\right]
\end{gathered}
$$

\section{Corollary}

(a) Only when the export sector of country 1 experiences technological progress, $z_{1}$ being ambiguous in sign, but $z_{2}>0$, and

(b) Only when the import sector of country 1 experiences technological progress, $z_{1}>0$, but $z_{2}<0$

(c) When both sectors undergo technological progress, the world income (defined as the sum of both countries' income) unambiguously increases,

and is completely distributed, i.e., $z_{1}+z_{2}=\hat{a}_{X 1} X_{1}+\hat{a}_{Y 1} Y_{1}>0$. Thus, technological progress is also a positive-sum game for the two countries.

The change in the real exchange rate, equation (21), for $0<\zeta<1 / 2$ as a plausible case for large countries (i.e., $2 \zeta-1<0$ ) means that the sign of $\hat{r e r}$ is opposite to that of $p-q$, ceteris paribus. Then, in view of our previous Proposition 5, the following Proposition 7 is immediate:

Proposition 7 The Changes in the Real Exchange Rate (The Harrod-Balassa- 
Samuelson predictions)

Retaining the assumptions in Proposition 5, technological progress in country 1 moves the real exchange rate to:

$$
\hat{r e r}=\frac{1}{\Delta}\left[m_{1} X_{1} \hat{a}_{X 1}-\left(1-m_{1}\right) Y_{1} \hat{a}_{Y 1}+\left(\hat{a}_{X 1}-\hat{a}_{Y 1}\right) \varepsilon_{X 1} X_{1}\right]
$$

which is ambiguous in sign.

\section{Corollary}

(a) $\hat{r e r}<0$ (i.e. real appreciation of country 1's currency) only when the import sector experiences technological progress, but

(b) $\hat{r e r}>0$ (i.e. real depreciation of country 1's currency) only when the export sector experiences technological progress.

It should be mentioned that the above Corollary reflects the price effects of technological progress on international trade. In case (a), technological progress in the import competing sector tends to lessen imports from country 2 , thereby reducing $\mathrm{Q}$ through a fall in demand, and thus the real exchange rate of country 1 appreciates. On the other hand, in case (b), technological progress in the export sector promotes exports to country 2 , and thereby reduces $\mathrm{P}$ through an increase in supply, and thus the real exchange rate depreciates. ${ }^{20}$

\section{The Effects of Monetary Integration: An Application and Interpretation}

The last section explored the effects of changes in factor endowment and technological progress on the terms of trade, the real income, and the real exchange rate between the two large countries. Applying those results, this section examines the effects of the creation or new accession to a monetary union for both member and non-member countries. ${ }^{21}$

In order to make our analysis tractable and easy to interpret practically, let us

\footnotetext{
${ }^{20}$ Camarero, Ordóez and Tamarit (2005) found that the productivity differences were statistically significant in almost all cases for their estimation of the long-run real exchange rate for 1970:1 to 1978:4 with the sample of 7 countries (including 4 euro area countries).

${ }^{21}$ For our present investigation of large countries case, creation of, or new accession to, a monetary union is equivalent qualitatively.
} 
suppose that country 1 stands for the group of European Union members that have adopted the euro as the single currency in the area, and country 2 for another large country, say the United States. As in section II, let us further suppose that there is another, possibly large country identified by suffix 0 , who is a new accession country to the EU and allowed to use the euro. Our interest rests on the effects of this new accession on the terms of trade, real income, and the real exchange rate for both the "ins" (consisting with countries 1 and 0 ) and "out" (country 2). For simplicity's sake, we assume that the production and trade structure is unchanged after the creation of, or new accession to, the monetary union. This implicitly assumes that the production functions before and after the monetary union are also unchanged, and the monetary union continues to export commodity $X$ and import $Y^{22}$

\section{The Effects of Increase in Factor Endowment}

Since our aim is to examine the effects of the creation of, or new accession to, a monetary union, we suppose that the factor endowment of "out" (country 2) is fixed. Thus, $\hat{K}_{2}=\hat{L}_{2}=0$, but $\hat{K}_{M}>0$ and $\hat{L}_{M}>0$ where $\hat{K}_{M}$ and $\hat{L}_{M}$ now stand for capital and labor of "ins" in a new monetary union, i.e. $K_{M}=K_{1}+K_{0}$ and $L_{M}=L_{1}+L_{0} .{ }^{23}$ The terms of trade for the monetary union move as equation (22) indicates: Assuming $k_{X M}-k_{Y M}>0$, a change in the terms of trade $p-q>0$ if and only if (24-1), or equivalently (24-2), holds. Thus, if and only if the latter condition $d K_{M}<\kappa d L_{M}$ is satisfied, the terms of trade for "ins" (the euro zone) improves, while those for "out" (the United States) deteriorates.

If we interpret this finding along the eastern enlargement of the EU, it implies that the terms of trade moves in favor of the euro zone after the enlargement, on condition that the euro zone becomes relatively more labor abundant in the sense that $d K_{M}<\kappa d L_{M}$ being satisfied, together with underlying assumptions of capital intensity $\left(k_{X M}-k_{Y M}>0\right)$ and the Marshall-Lerner condition $(\Delta>0)$ being satisfied.

Although the terms of trade improves for the existing monetary union because of its expansion with country 0 , it does not necessarily means a favorable change in the real income. In fact, the real income of the monetary union moves in either the

\footnotetext{
${ }^{22} \mathrm{It}$ is assumed that, as in section II, countries 1 and 0 have the same production functions for both $\mathrm{X}$ and Y, except the productivity parameters, $A_{X}$ and $A_{Y}$

${ }^{23}$ This subsection presupposes that there is no technological progress in both countries.
} 
direction of increase or decrease, as equation (26) suggests. However, the real income of country 2 moves according to equation (25), implying that $z_{2}<0$ if $d K_{M}<\kappa d L_{M}$ under our premised assumptions, i.e., $k_{X M}-k_{Y M}>0, \Delta>0$ with $\hat{K}_{2}=\hat{L}_{2}=0$. Since the condition $d K_{M}<\kappa d L_{M}$ is necessary and sufficient, we could infer that country 2 ("out") will be negatively affected by the creation of, or new accession to, a monetary union. Thus, from the standpoint of "out", eastern enlargement of the EU and the resultant widening of the euro zone would likely have an adverse effect on the real income of "out", depending on the underlying premises. However, as the corollary to Proposition 3 makes clear, the world real income, $z_{M}+z_{2}$, is unambiguously positive. This implies an important fact that, although the Corollary means that there is a gain (a positive-sum game) from creation of or new accession to a monetary union, there is a real transfer from country 2 ("out") to the monetary union ("ins") as the result of factor accumulation.

Proposition 4 predicts the possible direction of the real exchange rate movement. Under the present presumptions of $k_{X M}-k_{Y M}>0, \Delta>0, \hat{K}_{2}=\hat{L}_{2}=0,0<\zeta<1 /$ 2 and $d K_{M}<\kappa d L_{M}$, we can conclude that $\hat{r e} r<0$ because $p-q>0$. Thus, the real exchange rate of monetary union appreciates, implying that the rate of country 2 ("out") depreciates, ceteris paribus. ${ }^{24}$

\section{The Effects of Technological Progress}

This subsection examines the effects of technological progress because of the creation of, or new accession to, a monetary union (country 1 with 0 ) on the terms of trade, real income, and the real exchange rate. To emphasize the effects of technological progress experienced in country 1 (i.e. $\hat{a}_{i M}>0$ for $i=X, Y$ ), we assume $\hat{a}_{i 2}=0 .{ }^{25}$ Here, as before, we define $\hat{a}_{i M}$ as a positive linear convex combination of

\footnotetext{
${ }^{24}$ The actual nominal exchange rate of the euro against the US dollar depreciated for two years after its inception. Begg (2002), Bibow (2002), Arestis, Mariscal, Brown, and Sawyer (2002), Allegeret and Sandretto (2002), among others, examined and attributed the depreciation to policy and structural problems in the euro zone. Buiter and Grafe (2001) predicted that the nominal exchange rate of the euro is expected to appreciate in future, because of productivity gains from new accession countries. We will return to examine the latter issue in the next subsection. For explanation of the initial depreciation of the euro-dollar rate, see Khan, Khan, and Luintel (2002), Salvatole (2002), and Caporale and Cipollini (2002) who attributed the nominal depreciation mainly to the budget deficits, interest rate differentials, and non-transparency of economic policy, respectively.

${ }^{25}$ This assumption is an exaggeration, but may reflect the fact that labor productivity in some European countries are consistently higher than that of the other large countries such as the United Sates or Japan. See Cetle (2005) for international differences in labor productivity among OECD countries.
} 
$\hat{a}_{i 1}$ and $\hat{a}_{0}$, i.e. $\hat{a}_{i M} \equiv b_{i} \hat{a}_{i 1}+\left(1-b_{i}\right) \hat{a}_{i 0}$ for $i=X, Y$, where $0<b_{i}<1{ }^{26}$

The change in the terms of trade for the monetary union ("in"), which is now consists of country 1 and 0 , is expressed by modifying equation (28) to:

$$
p-q=\frac{-1}{\Delta Y_{2 M}}\left[m_{M} X_{M} \hat{a}_{X M}-\left(1-m_{M}\right) Y_{M} \hat{a}_{Y M}+\left(\hat{a}_{X M}-\hat{a}_{Y M}\right) X_{M} \varepsilon_{X M}\right]
$$

from which we can deduce that, assuming $\Delta>0$ for the monetary union:

$$
\begin{aligned}
p-q\left\{\begin{array}{l}
> \\
= \\
<
\end{array}\right\} 0 \text { according to whether } \\
\qquad\left[m_{M} X_{M} \hat{a}_{X M}-\left(1-m_{M}\right) Y_{M} \hat{a}_{Y M} \hat{a}_{Y M}+\left(\hat{a}_{X M}-\hat{a}_{Y M}\right) X_{M} \varepsilon_{X M}\right]\left\{\begin{array}{l}
> \\
= \\
<
\end{array}\right]
\end{aligned}
$$

The condition in (34') is both necessary and sufficient for the movement of the terms of trade for the monetary union.

If we further assume that only the import-competing sector of the monetary union undergoes technological progress $\left(\hat{a}_{Y M}>0\right.$ but $\left.\hat{a}_{X M}=0\right)$, then (34) yields:

$$
p-q=\frac{1}{\Delta Y_{2 M}}\left[\left(1-m_{M}\right) Y_{M}+X_{M} \varepsilon_{X M}\right] \hat{a}_{Y M}
$$

But, on the contrary, if technological progress is observed only in the export sector $\left(\hat{a}_{X M}>0\right.$ but $\left.\hat{a}_{Y M}=0\right)$, then, we have:

$$
p-q=\frac{-1}{\Delta Y_{2 M}}\left[m_{M} Y_{M}+X_{M} \varepsilon_{X M}\right] \hat{a}_{X M}<0
$$

Buiter and Grafe $(2001,2002)$ argued that productivity growth in the traded good sector of the candidate accession countries to the EMU is relatively faster, because of the "catch-up" process. If their observation is true, and if the productivity growth of the export sector has already been high enough as a result of international competition, then we could boldly assume that the productivity growth of the import competing sector of the monetary union is getting faster than that of the export sector. The reason for this lies in the fact that the import competing sector

\footnotetext{
${ }^{26}$ For similar definitions for a small country case, recall equation (11) in Section II. Here, $b_{i}$ is similarly assumed and interpreted.
} 
has had comparative disadvantage in world trade, and thus as a result of its new accession to a monetary union, the catch-up process would be required for some reasons such as the balance of payments consideration. Thus, we could suppose that, although our inference is subject to close empirical examination in the future, productivity growth after new accession to the EMU would be approximated by $\hat{a}_{Y M}>0$ and $\hat{a}_{X M}=0 .{ }^{27}$ Hence, we conclude that the terms of trade will move in favor of the monetary union, as equation (35-1) predicts.

Once the change in the terms of trade is determined, the change in the real income can be inferred from Proposition 6. If we continue to assume that a combination of $\hat{a}_{Y M}>0$ and $\hat{a}_{X M}=0$ as a plausible case, in the sense that it would reflect the EMU's new accession case more accurately as discussed above, then we could infer that:

$$
\begin{gathered}
z_{M}=\frac{1}{\Delta}\left[\left(\Delta-m_{M}+1\right) Y_{M}+X_{M} \varepsilon_{X M}\right] \hat{a}_{Y M}>0, \text { but } \\
z_{2}=\frac{1}{\Delta}\left[-\left(1-m_{M}\right) Y_{M}+X_{M} \varepsilon_{X M}\right] \hat{a}_{Y M}<0
\end{gathered}
$$

Thus, new accession to EMU is beneficial, in the sense it enhances the real income of EMU as a whole. ${ }^{28}$ However, the real income of "out" unambiguously falls. Since the total change in the real income of the world (defined as the sum of real income changes of "in" and "out") is $z_{M}+z_{2}=Y_{M} \hat{a}_{Y M}>0$, again implying a gain from creation from or new accession to a monetary union (a positive-sum game), we can derive an important message that there is the real transfer of income from "out" to "in". Thus, it should be emphasized that, under our premises, new accession to the EMU has a clear detrimental effect on the real income of "out".

The change in the real exchange rate can also be predicted retaining the assumptions of $\hat{a}_{Y M}>0$ and $\hat{a}_{X M}=0$. Recalling part (a) of Corollary to Proposition 7, we can infer that new accession to the EMU will bring about appreciation of the real exchange rate for the monetary union, which means depreciation of the currency of "out". Our prediction based on Proposition 7, about future appreciation of the common currency euro, is consistent with Buiter and Grafe $(2001,2002)$ who made a similar

\footnotetext{
${ }^{27}$ In other words, since the export sector $X$ has had comparative advantage, the "catch-up" process may not be required, implying $\hat{a}_{X M}=0$.

${ }^{28}$ It should be stressed that this result is the aggregated effect of new accession to EMU's real income. How the increment in the real income is distributed among members (country 1 and 0 ) is another problem not considered here.
} 
inference based on the Harrod-Balassa-Samuelson hypothesis in a small country framework explained in Section II.

Our inferences discussed above are, on the other hand, derived from a more explicit but plausible framework of a large-country model in which the terms of trade are determined by the interaction between the large countries, and through the change in the terms of trade by the creation of, or new accession to, a monetary union, the real incomes are affected and the real exchange rate is adjusted so as to keep the balance of payments in equilibrium.

\section{Conclusions}

This article focuses on one central question about the effects of forming or joining a monetary union both on itself ("ins") and on the outsiders ("out") as well. Although the latter effects have long been mentioned as a possibility of disguised protectionism in a form of regionalism, the formal analysis has been largely neglected in the literature.

We started our analysis with construction of a small country model embodying the effect of productivity, called as the Harrod-Balassa-Samuelson effect, in the production function. Solving the model, we have confirmed that the effects of forming or joining a monetary union has an important impact on both "ins" and "outs", as the real exchange rate possibly moves to the opposite direction between before and after the monetary union is formed or expanded.

Since a monetary union, however, necessarily implies not a "small" but a "large" entity, we recognized that examining the effects of a monetary union within a large country model is imperative. We reexamined those effects within the model with special attention to the change in the terms of trade between "ins" and "outs".

Recognizing the fact that forming or joining a monetary union has an equivalent characteristic of economic growth for "ins", we solved the model to derive the closed form for the change in the terms of trade under two different cases of economic growth, factor accumulation and technological progress. The change in the terms of trade and its effects on real income and the real exchange rate are summarized in Propositions 2, 3, and 4 for factor accumulation, and Propositions 5, 6 , and 7 for technological progress.

Using those Propositions, we interpreted the effects of the formation of or new accession to a monetary union, with the EMU in mind in section IV on the terms of trade, real income and the real exchange rate. 
It was shown that, on the one hand, under our assumed but plausible premises, the real exchange rate of the monetary union's currency is appreciated by economic growth in both senses of factor accumulation and technological progress. On the other hand, the real income is shown to always move against the "outs", and in this sense the formation of or new accession to a monetary union has a clear detrimental welfare effect on the "outs". However, since the world real income is shown to be increased by economic growth (i.e., a positive-sum game for the world economy), it was shown that there is a real transfer from "outs" to "ins".

It should be stressed that the above welfare effects and the change in the real exchange rate were driven by the terms of trade that was shown to move in favor of the monetary union, and it was through this change in the terms of trade that such predictions were brought about. Upon reflection, those results are quite plausible, as a monetary union is a "large" entity that could have a power to change the terms of trade in favor of itself.

A final but important message that cautions us is that the formation of or new accession to a monetary union always has a possibility of harmful adverse effects on "outs". This has been a reasonably standard argument against any kind of local or regional integrations, since a monetary union is nothing but one of the discriminating preferential trading systems, and thus the second-best solution at best for the world economy. Our analysis confirms and resurges a long-feared concern that a monetary union as a form of local or regional integrations could potentially work, whether intentionally or not, as a new device of protectionism against the "outs".

\section{Acknowledgement}

The research idea was fostered while the author was visiting at the University of Lausanne, where he had chances to discuss with Ioannis Papadopoulos, Jacques Dierzi, and Alexander Bergmann. The present research was initiated during his visit to Charles University in Prague. Thanks are due to Evzen Kocenda for stimulating discussions and Jose de Noguera for his suggestions to construct the analytical model. The author is grateful to Yukihiro Iida for comments and useful conversations at various stages of the writing of this paper. Comments and suggestions on an earlier version by Tatsuyoshi Miyakoshi, Jiro Akita, Akiomi Kitagawa, and other seminar participants at Tohoku University are gratefully acknowledged. The author alone is responsible for any errors that may remain. 


\section{References}

Alesina, Alberto and Barro, Robert J. "Currency Unions" Quarterly Journal of Economics 117(2), May 2002: 409-436

Allegret, Jean-Pierre and Sandretto, Ren "The Euro as a Stabilizing and Harmonizing Force in the International Monetary System : Analytical Foundations and Future Prospects" Eastern Economic Journal 28(1), Winter 2002: 105-120

Arestis, Philip, Mariscal, Iris Biefang-Frisancho, Brown, Andrew, and Sawyer, Malcolm "Explaining the Euro's Initial Decline" Eastern Economic Journal 28(1), Winter 2002: $71-88$

Arestis, Philip, Khan, Mosahid, and Luintel, Kul B. "Fiscal Deficits in Monetary Unions: A Comparison of EMU and United States" Eastern Economic Journal 28(1), Winter 2002: 89-103

Asea, Patrick K. and Mendoza, Enrique G. "The Balassa-Samuelson Model: A GeneralEquilibrium Appraisal," Review of International Economics 2(3), October 1994: 244267

Balassa, Bela "The Purchasing Power Parity Doctrine: A Reappraisal" Journal of Political Economy 72(6), December 1964: 584-596

Baldwin, Richard and Wyplosz, Charles The Economics of European Integration. Maidenhead: McGraw-Hill Education, 2004

Balvers, Ronald J. and Bergstrand, Jeffrey H. "Equilibrium Real Exchange Rates: Closedform Theoretical Solutions and Some Empirical Evidence," Journal of International Money and Finance 16(3), June 1997: 345-366

Begg, Iain "The Euro: A Success Against the Odds?" Eastern Economic Journal 28(1), Winter 2002: 25-44

Bibow, Jrg "The Market Versus The ECB, and the Euro's Plunge" Eastern Economic Journal 28(1), Winter 2002: 45-57

Buiter, Willem and Grafe, Clemens "Anchor, Float, or Abandon Ship: Exchange Rate Regimes for Accession Countries" EIB Papers 7(2), 2002: 51-71

Buiter, Willem and Grafe, Clemens "Central Banking and the Choice of Currency Regime in Accession Countries" SUERF Studies No. 11, 2001: 1-45

Camarero, Mariam, Ordez, Javier, and Tamarit, Cecillo "The Euro-Dollar Exchange Rate: Is It Fundamental?" in P. DeGrauwe (ed.) Exchange Rate Economics: Where Do We Stand? Cambridge, MA: The MIT Press, 2005: 277-306

Caporale, Guglielmo Maria and Cipollini, Andrea "The Euro and Monetary Transparency" Eastern Economic Journal 28(1), Winter 2002: 39-70

Carré, Martine and Collard, Fabrce "Monetary Union: A Welfare Based Approach" European Economic Review 47(3), June 2003: 521-552

Cette, Gilbert "Are Productivity Levels Higher in Some European Countries than in the United States?" International Productivity Monitor No.10, Spring 2005: 59-68

Ching, Stephen and Devereux, Michael B. "Mundell Revisited: A Simple Approach to the 
Costs and Benefits of a Single Currency Area" Review of International Economics 11(4), October 2003: 674-691

Dellas, Harris and Tavlas, George "The Global Implications of Regional Exchange Rate Regimes" Journal of International Money and Finance 24(2), March 2005: 243-255.

Faria, Joo Ricardo and Len-Ledesma, Miguel "Testing the Balassa-Samuelson Effect: Implications for Growth and the PPP," Journal of Macroeconomics 25(2), June 2003: 241-253

Frankel, Jeffrey and Rose, Andrew "An Estimation of the Effect of Common Currencies on Trade and Income" Quarterly Journal of Economics 117(2), May 2002: 437-466

Gandolfo, Giancarlo International Economics I: The Pure Theory of International Trade $\left(2^{\text {nd }}\right.$ rev. ed.) Berlin: Springer-Verlag, 1994

Froot, Kenneth A. and Rogoff, Kenneth "Perspectives on PPP and Long-run Real Exchange Rates," in G.M. Grossman and K. Rogoff (eds.) Handbook of International Economics, Vol. III. Amsterdam: Elsevier Science B.V., 1995: 1647-1688.

Harrod, Roy F. International Economics. London: James Nisbet and Cambridge University Press, 1933

Irandoust, Manuchehr and $\mathrm{Sj}$, Boo "Productivity and Real Exchange Rates: Some Empirical Examples," Journal of Economic Integration 17(3), September 2002: 527-553

Jensen, Bjarne S. and Wang, Chunyan "General Equilibrium Dynamics of Basic Trade Models for Growing Economies" in Bjarne S. Jensen and Kar-yiu Wong (eds.) Dynamics, Economic Growth, and International Trade. Ann Arbor: The University of Michigan Press, 1997: 77-126

Kollmann, Robert "Welfare Effects of a Monetary Union: The Role of Trade Openness" Journal of the European Economic Association 2(2-3), April-May 2004: 289-301.

Kowalczyk, Carsten "Welfare and Integration" International Economic Review 41(2), May 2000:483-494

Lafrance, Robert and St-Amant, Pierre "Optimum Currency Areaa: A Review of the Recent Literature" Bank of Canada Working paper N0.99-16, October 1999.

McCallum, Bennett T. "Theoretical Issues Pertaining to Monetary Unions" in F.H.Capie and G.E.Wood (eds.) Monetary Unions: Theory, History, Public Choice. London: Routledge, 2003: 7-25

Mark, Nelson C. and Choi, Doo-Yull "Real Exchange-Rate Prediction over Long Horizon" Journal of International Economics 43(1-2), August 1997: 29-60

Obstfeld, Maurice and Rogoff, Kenneth Foundations of International Macroeconomics. Cambridge, MA: The MIT Press, 1996, chapters 4 and 9

Rogoff, Kenneth "Traded Goods Consumption Smoothing and the random Walk Behavior of the Real Exchange Rate" NBER Working Paper No. 4119, July 1992

Salvatore, Dominick "The Euro: Expectations and Performance" Eastern Economic Journal 28(1), Winter 2002: 121-135

Samuelson, Paul A. "Theoretical Notes on Trade Problems" Review of Economics and Statistics 46(2), May 1964: 145-154

Sarno, Lucio and Taylor, Mark P. The Economics of Exchange Rate. Cambridge, Cambridge 
University Press, 2002

Takayama, Akira International Trade: An Approach to Theory. New York: Holt, Rinehart, and Winston, Inc., 1972

von Furstenberg, George M. and Teolis, David P. "Should Small Countries Join an Existing Monetary Union?” Journal of Economic Integration 17(1), March 2002: 104-132

\section{Appendix}

This section presents some mathematical formulae derived in our large country model in Section III.

Assuming the solvability condition for the system of equation (14-5), it is solved for the four variables as follows:

$$
\begin{aligned}
& \hat{K}_{X}=\frac{1}{k_{X}-k_{Y}}\left\{\frac{K}{L_{X}}\left(\hat{K}-k_{Y} \frac{L}{K} \hat{L}\right)-\frac{k_{Y}}{L_{X}}\left[\frac{L_{X}}{k_{X}}\left(\frac{1-\theta_{L X}}{\theta_{L X}}\right)+\frac{L_{Y}}{k_{Y}}\left(\frac{1-\theta_{L Y}}{\theta_{L Y}}\right)\right](\hat{W}-\hat{R})\right\} \\
& \hat{L}_{X}=\frac{1}{k_{X}-k_{Y}}\left\{\frac{K}{L_{X}}\left(\hat{K}-k_{Y} \frac{L}{K} \hat{L}\right)-\frac{1}{L_{X}}\left[\frac{K_{X}}{k_{X}}\left(\frac{1-\theta_{L X}}{\theta_{L X}}\right)+\frac{K_{Y}}{k_{Y}}\left(\frac{1-\theta_{L Y}}{\theta_{L Y}}\right)\right](\hat{W}-\hat{R})\right\} \\
& \hat{K}_{Y}=\frac{-1}{k_{X}-k_{Y}}\left\{\frac{K}{L_{Y}}\left(\hat{K}-k_{X} \frac{L}{K} \hat{L}\right)-\frac{k_{X}}{L_{X}}\left[\frac{L_{X}}{k_{X}}\left(\frac{1-\theta_{L X}}{\theta_{L X}}\right)+\frac{L_{Y}}{k_{Y}}\left(\frac{1-\theta_{L Y}}{\theta_{L Y}}\right)\right](\hat{W}-\hat{R})\right\} \\
& \hat{L}_{Y}=\frac{-1}{k_{X}-k_{Y}}\left\{\frac{K}{L_{Y}}\left(\hat{K}-k_{X} \frac{L}{K} \hat{L}\right)-\frac{1}{L_{Y}}\left[\frac{L_{X}}{k_{X}}\left(\frac{1-\theta_{L X}}{\theta_{L X}}\right)+\frac{L_{Y}}{k_{Y}}\left(\frac{1-\theta_{L Y}}{\theta_{L Y}}\right)\right](\hat{W}-\hat{R})\right\}
\end{aligned}
$$

Differentiation of production function yields:

$$
\begin{gathered}
\hat{X}=\theta_{L X} \hat{L}_{X}+\left(1-\theta_{L X}\right) \hat{K}_{X}+\hat{a}_{X} \\
\hat{Y}=\theta_{L Y} \hat{L}_{Y}+\left(1-\theta_{L Y}\right) \hat{K}_{Y}+\hat{a}_{Y}
\end{gathered}
$$

Substitution of (A1-1) - (A1-4) into (A2-1) and (A2-2) yields:

$$
\begin{aligned}
\hat{X}= & \frac{1}{k_{X}-k_{Y}}\left[\frac{K}{L_{X}}\left(\hat{K}-k_{Y} \frac{L}{K} \hat{L}\right)\right]-\frac{(\hat{W}-\hat{R})}{L_{X}\left(k_{X}-k_{Y}\right)} \\
& \left\{\frac{1-\theta_{L X}}{k_{X} \theta_{L X}} L_{X}\left[\theta_{L X} k_{X}+\left(1-\theta_{L X}\right) k_{Y}\right]+\left(\frac{1-\theta_{L Y}}{\theta_{L Y}}\right) L_{Y}\right\}+\hat{a}_{X}
\end{aligned}
$$




$$
\begin{aligned}
\hat{Y}= & \frac{1}{k_{X}-k_{Y}}\left[\frac{-K}{L_{X}}\left(\hat{K}-k_{X} \frac{L}{K} \hat{L}\right)\right]+\frac{(\hat{W}-\hat{R})}{L_{Y}\left(k_{X}-k_{Y}\right)} \\
& \left\{L_{X} \frac{1-\theta_{L X}}{\theta_{L X}}+\frac{1-\theta_{L Y}}{k_{Y} \theta_{L Y}} L_{Y}\left[\theta_{L Y} k_{Y}+\left(1-\theta_{L Y}\right) k_{X}\right]\right\}+\hat{a}_{Y}
\end{aligned}
$$

On the other hand, since (12-1) and (12-2) exhibit homogeneous of degree one with respect to two factors of production, the Euler equation implies:

$$
\begin{aligned}
& \hat{X}=\theta_{L X} \hat{L}_{X}+\theta_{L X} \hat{\mu}_{X}+\left(1-\theta_{L X}\right) \hat{K}_{X}+\left(1-\theta_{L X}\right) \hat{\nu}_{X} \\
& \hat{Y}=\theta_{L Y} \hat{L}_{Y}+\theta_{L Y} \hat{\mu}_{Y}+\left(1-\theta_{L Y}\right) \hat{K}_{Y}+\left(1-\theta_{L Y}\right) \hat{v}_{Y}
\end{aligned}
$$

Thus, equations (A-3) and (A-4) together imply:

$$
\begin{gathered}
\theta_{L X} \hat{\mu}_{X}+\left(1-\theta_{L X}\right) \hat{v}_{X}=\hat{a}_{X} \\
\theta_{L Y} \hat{\mu}_{Y}+\left(1-\theta_{L Y}\right) \hat{v}_{Y}=\hat{a}_{Y}
\end{gathered}
$$

Utilizing the initial conditions $P=Q=1$, equation (13) in the text implies:

$$
\begin{aligned}
& p-q+\hat{\mu}_{X}=\hat{\mu}_{Y} \\
& p-q+\hat{v}_{X}=\hat{v}_{Y}
\end{aligned}
$$

where $p \equiv d P / P=\hat{P}$ and $p \equiv d Q / Q=\hat{Q}$. Thus, rearranging equations (13), (A5) and (A6) yields:

$$
p-q+\left(\hat{a}_{X}-\hat{a}_{Y}\right)=\left(\theta_{L X}-\theta_{L Y}\right)(\hat{W}-\hat{R})
$$

Rearranging the Euler equations, together with the production functions (12) and the profit maximization conditions (13), implies:

$$
\theta_{L X}=\left(\frac{W}{R}\right) /\left(k_{X}+\frac{W}{R}\right) \text { and } \theta_{L Y}=\left(\frac{W}{R}\right) /\left(k_{Y}+\frac{W}{R}\right)
$$

and, hence:

$$
\theta_{L X}-\theta_{L Y}=\left[\left(\frac{W}{R}\right)\left(k_{X}-k_{Y}\right)\right] /\left[\left(k_{X}+\frac{W}{R}\right)\left(k_{Y}+\frac{W}{R}\right)\right]
$$

Thus, it is clear from (A9) that $\theta_{L X}>(<) \theta_{L Y}$ according to whether $k_{X}>(<) k_{Y}$. We should explain the several definitions introduced in the process of our analysis to simplify our formulae. The elasticity of production, $\varepsilon_{i}(i=X, Y)$ is defined as: 


$$
\varepsilon_{X} \equiv \frac{(P / Q)}{X} \frac{d X}{d(P / Q)}=\frac{1}{X} \frac{x}{p-q} \text { and } \varepsilon_{Y} \equiv \frac{(P / Q)}{Y} \frac{d Y}{d(P / Q)}=\frac{1}{Y} \frac{y}{p-q}
$$

where $\varepsilon s$ are evaluated at the initial equilibrium conditions $P=Q=A_{i}=1$ and $\hat{K}=\hat{L}=0 .{ }^{29}$ Substitution of (A4), (A5) and (A7) into (A10) yields:

$$
\begin{aligned}
& \varepsilon_{X}=\frac{\alpha_{X}}{\left(k_{X}-k_{Y}\right)\left(\theta_{L Y}-\theta_{L X}\right)} \text { where } \alpha_{X} \equiv\left\{\frac{1-\theta_{L X}}{k_{X} \theta_{L X}}\left[\theta_{L X} k_{X}+\left(1-\theta_{L X}\right) k_{Y}\right]+\frac{1-\theta_{L Y}}{\theta_{L Y}}\left(\frac{L_{Y}}{L_{X}}\right)\right\} \\
& \varepsilon_{Y}=\frac{\alpha_{Y}}{\left(k_{X}-k_{Y}\right)\left(\theta_{L Y}-\theta_{L X}\right)} \text { where } \alpha_{Y} \equiv\left\{\frac{1-\theta_{L Y}}{k_{Y} \theta_{L Y}}\left[\theta_{L Y} k_{Y}+\left(1-\theta_{L Y}\right) k_{X}\right]+\frac{1-\theta_{L X}}{\theta_{L X}}\left(\frac{L_{X}}{L_{Y}}\right)\right\}
\end{aligned}
$$

Since equation (A9) implies that $\left(\theta_{L X}-\theta_{L Y}\right)$ and $\left(k_{Y}-k_{X}\right)$ have the same sign, equation (A11) in turn implies that $\varepsilon_{X}>0$ and $\varepsilon_{Y}>0 .^{30}$

We also define the elasticity of export supply and the elasticity of import demand. In order to make the concepts clear and our discussions concrete, we assume that $X_{12}$ is the export of $X$ from country 1 to 2 , while $Y_{21}$ is that from country 2 to 1 . Then, the elasticity of export supply is defined as:

$$
\varepsilon_{1}^{\prime} \equiv \varepsilon_{X 1} \frac{X_{1}}{X_{12}} \text { and } \varepsilon_{2}^{\prime} \equiv \varepsilon_{X 2} \frac{X_{2}}{X_{21}}
$$

where the elasticity of import demand is:

$$
\eta_{1}^{\prime} \equiv \eta_{1} \frac{\left(Y_{1}+Y_{21}\right)}{Y_{21}} \text { and } \eta_{2}^{\prime} \equiv \eta_{2} \frac{\left(X_{2}+X_{12}\right)}{X_{12}}
$$

where $\eta_{1} \equiv \frac{Q / P}{Y_{1}+Y_{21}} \frac{\partial Y_{21}}{\partial(Q / P)}$ and $\eta_{2} \equiv \frac{P / Q}{X_{1}+X_{12}} \frac{\partial X_{12}}{\partial(P / Q)}$.

It should be pointed out that, if there is no change in the factor endowment $(\hat{K}=\hat{L}=0)$ and technological progress $\left(\hat{a}_{X}=\hat{a}_{Y}=0\right), x(\equiv d X)$ and $y(\equiv d Y)$ refer to the movement along the production possibility frontier because of our assumption of perfect competition. Since $P=Q=1$ is assumed initially, $x_{i}+y_{i}=0$

\footnotetext{
${ }^{29}$ It should be noted that $\mathcal{\varepsilon} s$ can be different between countries. Thus, unlike the standard HeckscherOhlin model where production function of the same good is identical across countries, we do not impose such an assumption.

${ }^{30}$ Both $\alpha_{X}$ and $\alpha_{Y}$ are positive in equation (A11).
} 
$(i=1,2)$ under the circumstance. Hence we have:

$$
\varepsilon_{X i} X_{i}=\varepsilon_{Y i} Y_{i} \quad(i=1,2)
$$

Using those definitions and relationships, (A11) and (A14), equation (A3) is simplified as:

$$
\begin{gathered}
\hat{X}=\frac{\lambda_{X}}{k_{X}-k_{Y}}+\varepsilon_{X}(p-q)+\varepsilon_{X}\left(\hat{a}_{X}-\hat{a}_{Y}\right)+\hat{a}_{X} \\
\hat{Y}=\frac{-\lambda_{Y}}{k_{X}-k_{Y}}-\varepsilon_{Y}(p-q)+\varepsilon_{Y}\left(\hat{a}_{Y}-\hat{a}_{X}\right)+\hat{a}_{Y}
\end{gathered}
$$

where:

$$
\lambda_{X} \equiv\left(K / L_{X}\right)\left(\hat{K}-k_{Y} L \hat{L} / K\right) \text { and } \lambda_{Y} \equiv\left(K / L_{Y}\right)\left(\hat{K}-k_{X} L \hat{L} / K\right)
$$

The last equations are (16-1), (16-2), and (16-3) in the text. This completes the description of the supply side of our model.

We now present the description of the demand side of the economy. The import demand function for each country is assumed as in equation (17) in the text. Differentiation of (17), together with the assumption of the initial equilibrium of the balance of payment, yields:

$$
\begin{aligned}
& y_{1}+y_{21}=-\left(Y_{1}+Y_{21}\right)(q-p) \eta_{1}+m_{1}\left[(p-q) Y_{21}+x_{1}+y_{1}\right] \\
& x_{1}+x_{12}=-\left(X_{1}+X_{12}\right)(p-q) \eta_{2}+m_{2}\left[(q-p) Y_{21}+x_{2}+y_{2}\right]
\end{aligned}
$$

where $m_{i}$ is the marginal propensity to consume the imported goods in the i-th country. The balance of payments (trade balance) for country 1 is defined as:

$$
B_{1}=P_{1} X_{12}-Q_{2} Y_{21}
$$

Assuming that the balance of payments is initially in balance, and $P_{i}=Q_{i}=1$ initially (i.e., $X_{12}=Y_{21}$ ), differentiation of (A17) yields:

$$
b_{1}=(p-q) Y_{21}+x_{12}-y_{21}=0
$$

Combining (A16) and (A18), together with the definitions (A13), yields:

$$
m_{1} x_{1}-\left(1-m_{1}\right) y_{1}+\left(1-m_{2}\right)-m_{2}=-(p-q) Y_{21}\left[\eta_{1}^{\prime}+\eta_{2}^{\prime}+m_{1}+m_{2}-1\right]
$$

which is equation (18) in the text. The coefficient of the right-hand side of equation (A19) is defined as: 


$$
\Delta \equiv \eta_{1}^{\prime}+\eta_{2}^{\prime}+m_{1}+m_{2}-1
$$

which is the Marshall-Lerner condition, equation (19) in the text.

In order to help our calculation further, we utilize three important relationships that should be clarified below. First, using (A11-1) and (A11-2), it can be shown that:

$$
\alpha_{X} X=\alpha_{Y} Y
$$

Second, from $\lambda_{X}$ and $\lambda_{Y}$ appeared in equation (A15), it can also be shown that:

$$
\lambda_{X} X-\lambda_{Y} Y=\left(v_{X} k+\mu_{X} l\right)\left(k_{X}-k_{Y}\right)
$$

Third, with equations (A14), (A15), (A21) and (A22), we have:

$$
x+y=\frac{\lambda_{X} X-\lambda_{Y} Y}{k_{X}-k_{Y}}+\hat{a}_{X} X+\hat{a}_{Y} Y=\left(v_{X} k+\mu_{X} l\right)+\hat{a}_{X} X+\hat{a}_{Y} Y
$$

